\title{
Systematically varied interfaces of continuously reinforced glass fibre/polypropylene composites: Comparative evaluation of relevant interfacial aspects
}

\author{
J. Rausch, R. C. Zhuang, E. Mäder* \\ Department of Composites, Leibniz Institute of Polymer Research Dresden, Hohe Strasse 6, 01069 Dresden, Germany
}

Received 10 May 2010; accepted in revised form 9 June 2010

\begin{abstract}
Interface related mechanical properties of unidirectional continuous glass fibre (GF)/polypropylene (PP) composites made of commingled yarns have been systematically studied according to a three level, three-factor factorial design. The three systematically varied factors comprised different silane coupling agent and film former contents in GF sizings as well as a varying GF diameter. Besides the statistical evaluation of those main effects on the transverse tensile and compression shear strengths of the composites, interfacial shear strength measurements on model composites have been performed. The latter ones as well as the results of the dynamic mechanical thermal analysis support the statistical significance of sizing components, the sizing content on the GF, and GF diameter for the mechanical properties of the composites. This highlights the interplay of proper sizing formulation and reproducible GF-spinning conditions, as both affect the interfacial bonding of continuously reinforced GF/PP composites.
\end{abstract}

Keywords: polymer composites, adhesion, coatings, reinforcements, mechanical properties

\section{Introduction}

In order to take advantage of the reinforcing ability of fibres in composite materials, the external stress is transferred to the fibres via the fibre/matrix interface. Thus, the composites properties are not only limited by the characteristics of the reinforcing fibres and the matrix polymer, but are affected to a great extent by the interfacial bonding between fibre and matrix as well as the interphasial properties. The interphase is a three dimensional region between fibre and matrix, mainly formed by the interdiffusion of the sizing and the matrix in the course of composite consolidation. The local properties, such as thermal, mechanical, chemical, and morphological characteristics are different from the ones of the surrounding bulk matrix.

Nowadays, the existence of a transition region between fibre and matrix is widely accepted and new characterization methods revealed locally different properties within a region of a few tens to a few hundreds of nanometers [1-5]. Sizing chemistry and interdiffusion play a great part in the development of interphases, which have been investigated in our earlier work [5]. When the sizing layer becomes the 'weak point' of the system, failure occurs within it $[4,6,7]$.

Considering GF sizings, which commonly amount to $0.5-1 \%$ of the fibre weight [8], their formulation consists of mainly three constituents: organofunctional silanes, polymeric film formers, and processing aids. The primary importance of organofunctional silanes is their ability to serve as an adhesion promoter or coupling agent providing a link between the matrix and the fibre surface by covalent bonding [9]. Polymeric film formers represent the biggest weight fraction in GF sizings. Besides

*Corresponding author, e-mail: emaeder@ipfdd.de

(c) BME-PT 
their vital importance for fibre protection and processability of the yarns, they affect the wetting of the fibre as well as the distribution of the silane on the fibre surface and consequently the mechanical performance of the composites [10]. Processing aids can include substances providing anti-static properties and lowering the friction during spinning and textile processing. Besides conventional sizing formulations, recent studies report on the incorporation of nanoparticles into aqueous sizings or coatings for enhanced fibre matrix adhesion [11-13] or functionalisation of the interphase by creating diffusion barriers [14]. Moreover, nanoparticles, namely carbon nanotubes, have been used for interphasial strain sensing [15-18].

Upon consolidation of the composites, interdiffusion of the sizing constituents with the matrix polymer takes place, resulting in graded physical properties within a transition zone, i.e. the interphase, between the fibre and the bulk polymer [7]. As the film former content in GF sizings is comparably high, its amount on the fibre surface as well as its chemical composition largely influence the evolution of the interphase [19]. Due to the currently available characterization techniques, the interphase dimensions and properties can be detected directly. In this context, atomic force microscopy (AFM) related measurements, e.g. phase imaging, nano-scratch and nano-indentation [5, 20, 21] or the use of microthermal analysis [22, 23] have revealed gradient properties as well as the local extension of the interphase for several fibre/matrix systems. Additionally, the effects of different fibre treatments, including the application of different silanes, film formers and coatings have been studied and related to the mechanical properties of the composites [24-27]. Regarding the local extension of the interphase, it was mentioned that increasing the interphases thickness could turn them into 'weak spots' with regard to the mechanical performance of the composites [4, 6]. However, the interphase related properties do not solely depend on the local extension of the interphase, but rather depend on a complex interplay of many factors. To date, a large body of literature contributing information to silanes and interfacial or interphasial issues in composites materials is available. Reviews on certain aspects can be found in [2, 9, 28-30].

This study is concerned with the systematic evaluation of a sizing system, consisting of $\gamma$-amino- propyltriethoxysilane (APS) and a PP film former, and its effect on interphase dominated micro and macro mechanical properties of continuously GF reinforced PP. The effects of the different sizing contents and formulations on the composite properties are evaluated statistically following a factorial design approach. Besides the constituents of the sizing formulation, the GF diameter, accounting for different surface areas and thus varying the average sizing thickness has been included into the factorial design. This approach allows determining the importance and interplay of the above mentioned factors on the dependent variables, i.e. the composites transverse and compression shear strength. In conjunction with the results of the factorial design by means of other methods, e.g. single fibre pullout (SFPO) tests, dynamic mechanical thermal analysis (DMA), differential scanning calorimetry (DSC) and high temperature gel permeation chromatography (HT-GPC), additional information on selected composites and composites properties is presented providing an insight into the mechanisms of interphase related composite failure.

\section{Experimental}

\section{1. Composite manufacturing}

Hybrid yarns, consisting of E-glass and PP filaments (approximately $50 \mathrm{vol} \% \mathrm{GF}$ ) were spun as described elsewhere [31]. For the spinning of the polymeric filaments the PP (HG455 FB from Borealis, Germany; weight average molecular weight $\left(M_{w}\right)=217600 \mathrm{~g} / \mathrm{mol}$, melt flow rate (ISO 1133): $27 \mathrm{~g} / 10 \mathrm{~min}$ ) was melt blended with $2 \mathrm{wt} \%$ maleic anhydride grafted polypropylene (MAH-PP) (Exxelor PO1020 from Exxon mobile, USA; $M_{w}=$ $86000 \mathrm{~g} / \mathrm{mol}$ ). During the spinning process, different sizings based on APS and a PP film former were applied on the GF. The latter one is a MAHPP based aqueous dispersion (Permanol 602 from Clariant, Switzerland), with $M_{w}=147600 \mathrm{~g} / \mathrm{mol}$ and a mean particle size of approximately $100 \mathrm{~nm}$. The sizing content was determined quantitatively by pyrolysis following DIN EN ISO 1172 .

The manufacturing of the unidirectional specimens for mechanical testing was achieved by filament winding of the hybrid yarns on a rotating steel core. The textile preform was compression moulded (KV 207 , Rucks $\mathrm{GmbH}$, Germany) at $225^{\circ} \mathrm{C}$ for $45 \mathrm{~min}$ in a computer controlled long term cycle (heating, 
consolidation and cooling in the mould). In detail, heating from ambient temperature to $225^{\circ} \mathrm{C}$ took $23 \mathrm{~min}$ at a pressure of $0.5 \mathrm{MPa}$, followed increasing the pressure to $3 \mathrm{MPa}$ for $2 \mathrm{~min}$, before cooling down to $40^{\circ} \mathrm{C}$ within $20 \mathrm{~min}$. During the cooling pressure was kept constant at $3 \mathrm{MPa}$. As determined by pyrolysis, the GF content of all specimens was determined to be $74 \pm 1.5 \mathrm{wt} \%$, equal to $\sim 50$ vol\%

\section{2. Mechanical testing and characterization}

The transverse tensile strength was measured according to specification ISO 527-5 with a velocity of $1 \mathrm{~mm} \cdot \mathrm{min}^{-1}$ for at least 10 specimens $(2 \times$ $10 \times 140 \mathrm{~mm}^{3}$ ) of each test series. Compression shear strength (CST) of the unidirectional composites was determined using a self-made testing device according to [32]. The CST test is a method for determining the apparent inter- and intralaminar shear strength of continuous fibre reinforced composites and involves a nearly pure and homogeneous shear load in the fracture plane of the specimen. Detailed information on the test setup is described elsewhere [32]. 10 specimens with the dimensions of $4 \times 10 \times 10 \mathrm{~mm}^{3}$ were tested at $1 \mathrm{~mm} \cdot \mathrm{min}^{-1}$. Similar to the determination of the transverse tensile strength, the mechanical characterisation was performed on a UPM 1456 from Zwick GmbH \& Co KG, Germany. For the determination of the interfacial shear strength (IFSS), SFPO measurements were performed on GF embedded $800 \mu \mathrm{m}$ into the same matrix as used for the unidirectional composites. Details of the test setup are described elsewhere [33]. The Differential Scanning Calorimetry (DSC) measurements of the matrix PP as well as the film former was performed on a Q2000 (TA Instruments, USA) under nitrogen atmosphere in a temperature range from -50 to $205^{\circ} \mathrm{C}$ with a heating/cooling rate of $10 \mathrm{~K} / \mathrm{min}$. All samples had been dried in a vacuum oven at $23^{\circ} \mathrm{C}$ for $3 \mathrm{~h}$ prior to DSC measurement. DMA on the composites was performed on a Q800 (TA Instruments, USA) calibrated with standardized steel plates by TA instruments. The temperature calibration of the DMA was performed using an indium standard. The specimens were tested in transverse fibre direction using a single cantilever bend mode with an amplitude of $20 \mu \mathrm{m}$. The fre- quency was set to $1 \mathrm{~Hz}$ and the heating rate was $1 \mathrm{~K} / \mathrm{min}$.

The scanning electron microscopy (SEM) micrographs were obtained using an Ultra 55 (Carl Zeiss SMT AG, Germany), after sputtering a $5 \mathrm{~nm}$ thick platinum layer onto the samples. The molecular weight of the matrix PP and the PP film former was determined by high temperature gel permeation chromatography (HT-GPC) at $150^{\circ} \mathrm{C}$ on a GPC220 (Varian Inc., USA) equipped with 2 PL mixed B LS columns using triple detection (refractive index, light scattering, and viscosity). 1,2,4-trichlorobenzene was used as solvent and eluent with a flow rate of $1 \mathrm{ml} / \mathrm{min}$

\subsection{Statistical analysis of the factorial design}

Composites with different sizing formulations and varying GF diameters, according to a three level, three-factor factorial design, were prepared. The chosen Box-Behnken design resulted in 15 experiments shown in Table 1. Besides the stepwise variation of the average GF diameter, the amount of silane and film former within the sizing formulation were changed. In the case of the GF diameter the indications '-', ' 0 ', and ' + ' are related to diameters of 11,13 and $16.5 \mu \mathrm{m}$, respectively. For the silane and film former the indications '-', ' 0 ', '+'refer to $0,1.5,3.0 \mathrm{wt} \%$ and $1.75,7.875$, $17.5 \mathrm{wt} \%$ solid content of the sizing, respectively. In the case of the film former, the lower and upper concentration result in less than 0.5 and around $2 \mathrm{wt} \%$ of organic content on the GF, respectively. The statistical analysis of the experimental results was performed by analyzing the factorial design with a statistical software (Statgraphics, Centurion). By creating regression equations a model fit was obtained relating the results of the mechanical testing to main and secondary effects, respectively. The former ones are in this case the silane and film former content of the sizing as well as the GF diameter, whereas the secondary effects describe quadratic contributions of the main effects or interactions between different main effects. Analysis of variance (ANOVA) allows determining the statistical significance of each effect by comparing the mean square of the model fit against an estimate of the experimental error. If the resulting P-values for the observed effects are less than 0.05 this is an 
indication that they are significantly different from zero at the $95 \%$ confidence level. Moreover, the correlation coefficient $R^{2}$ for the model is calculated providing a measure for the accuracy of the model fit. In order to establish a ranking of the importance of the observed effects, Pareto charts [34] can be created showing the statistical significance of each effect as a measure of its standardized effect.

\section{Results and discussion}

\subsection{Statistical analysis: Effect of factor variation on composite interfacial strength}

Following the factorial design and the stepwise variation of the three factors, the estimated response surfaces represent the best fit to the experimentally obtained values. Figure 1a shows the estimated response surface for the transverse tensile strength as a function of silane and film former contents in the sizing. It can be seen that the transverse tensile strength is highly influenced by the silane content. For the sizings without silane, the transverse tensile strength is found to range at very low values of about $5 \mathrm{MPa}$. However, at $1.5 \mathrm{wt} \%$ silane the transverse tensile strength has considerably improved, being between 20 and $25 \mathrm{MPa}$. A further increase of the silane content did not result in enhanced composite strength, the values are comparable to those at $1.5 \mathrm{wt} \%$ silane, however, the estimated response surface indicates maximum composite strengths between 1.5 and $3 \mathrm{wt} \%$ silane. This is related to the parabolic fitting of the estimated surface, although it has been reported that excess silane results in an increased build-up of physisorbed silane layers which can lower the interfacial strength $[10,35]$.

Regarding the film former, at all silane contents investigated a slight increase of the transverse tensile strength with decreasing film former content can be observed (Figure 1a). However, the effect is much less pronounced than the one of the silane content. The effect of the GF diameter is also statistically significant, but less important for the transverse tensile strength than that of the film former. The regression equation for the estimated response surface of the transverse tensile strength, $\sigma_{90^{\circ}}$, is given by Equation (1):
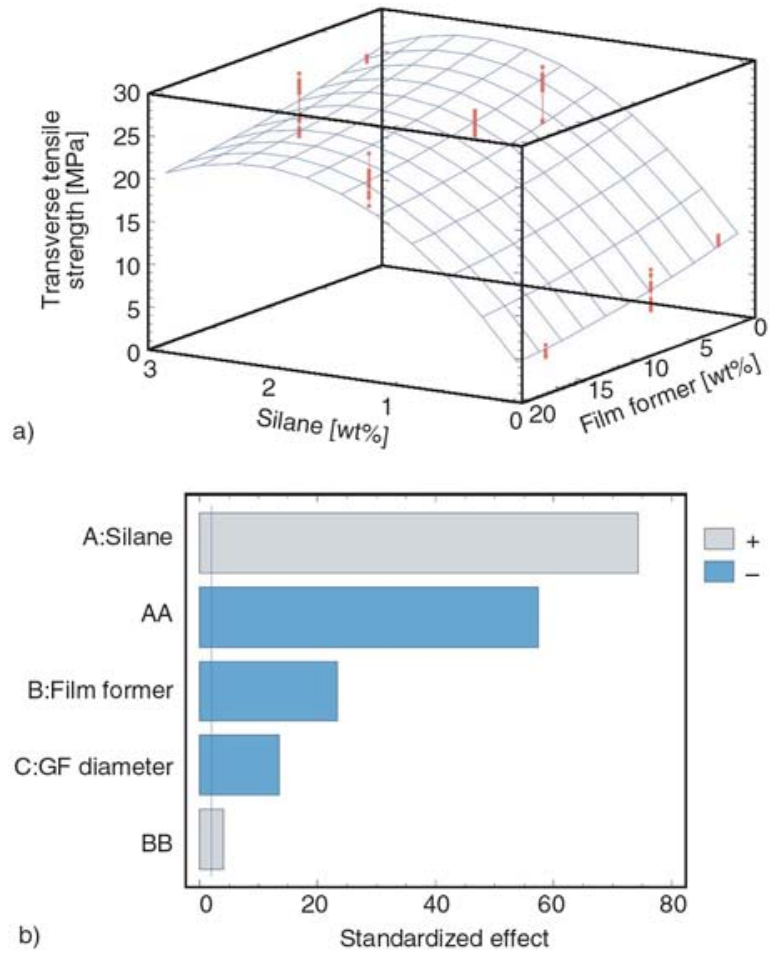

Figure 1. a) Estimated response surface for the transverse tensile strength of the GF/PP composites. The GF diameter was hold constant at $13 \mu \mathrm{m}$. The $\mathrm{wt} \%$ of silane and film former refers to the solid content of the applied sizings. b) Pareto chart showing the statistically significant effects for the transverse tensile strength of the GF/PP composites. A, B, and $\mathrm{C}$ denote the main effects (silane and film former content of the sizing, and GF diameter). Statistically significant secondary effects, describing quadratic contributions of the main effects or interactions between different main effects, respectively, are denoted by a twoletter combination of the corresponding main effects.

$$
\begin{aligned}
\sigma_{90^{\circ}}= & 16.1+16.86 \cdot A-0.43 \cdot B-0.47 \cdot C- \\
& 3.8 \cdot A^{2}+0.01 \cdot B^{2}
\end{aligned}
$$

where $A$ denotes the silane and $B$ the film former content of the sizing, respectively. Both quantities refer to wt\% relative to the solid content of the sizings. $C$ is the GF diameter in $\mu \mathrm{m}$. For Equation (1), the corresponding correlation coefficient $R^{2}$ is 0.98 . For the discussion of the statistical significance of the main and secondary effects the Pareto chart, presented in Figure 1b, gives a clear indication which factors are of importance to the transverse tensile strength. It shows the ranking of all statistically significant effects with P-values well below 0.05 . This includes the main effects, like the amount of silane and film former in the sizing and the GF 
diameter, but as well possible quadratic contributions of the main effects like $\mathrm{AA}$ and $\mathrm{BB}$, reflected in the curved shaped of the estimated response surface. Moreover, interactions between the main effects, e.g. AB, could be displayed, but those were found not to be significant for the transverse tensile strength. The limit for the statistical significance is indicated by the vertical line in the Pareto chart. As can be seen in Figure 1b, the silane content has the largest influence of all main effects, followed by the film former content and the GF diameter. For the latter one a linear correlation with the transverse tensile strength is found, whereas the other main effects are non-linear. The ' + ' and '-' in the Pareto chart indicate a positive and negative correlation with the transverse tensile strength, respectively. To put it simply, it can be summarized that a higher silane content in the sizing has a beneficial effect on the transverse tensile strength, whereas an increased film former content as well as a higher GF diameter result in lower values.

Similar to the transverse tensile strength, the dependence of the CST on the main effects was analyzed. Figure 2 a shows the estimated response surface as a function of solid content of silane and film former in the sizing. Again, the lowest CST values are found for the sizings without silane, however, compared with Figure 1a the influence of the film former is much more pronounced. While for the transverse tensile strength different film former contents in the sizings affect the absolute values only to a minor extent, the CST is found to be very sensitive to a variation in the film former content of the sizing. Figure $2 b$ shows the ranking of the statistical significance for the fitted estimated response surface in Figure 2a. Among the main effects, the film former is found to be the most significant factor, followed by the GF diameter and the silane content, respectively. Moreover, compared with the Pareto chart of the transverse tensile strength all secondary effects are found to be of statistical significance and contribute to the obtained results. This serves as a good example to demonstrate possible difficulties upon the interpretation of Pareto charts and the related estimated response surfaces. While the statistical analysis aims at the best fit of the experimental results, including secondary interactions as factors in the regression equation, their physical interpretation is not always straightforward. However, for the sake of com-

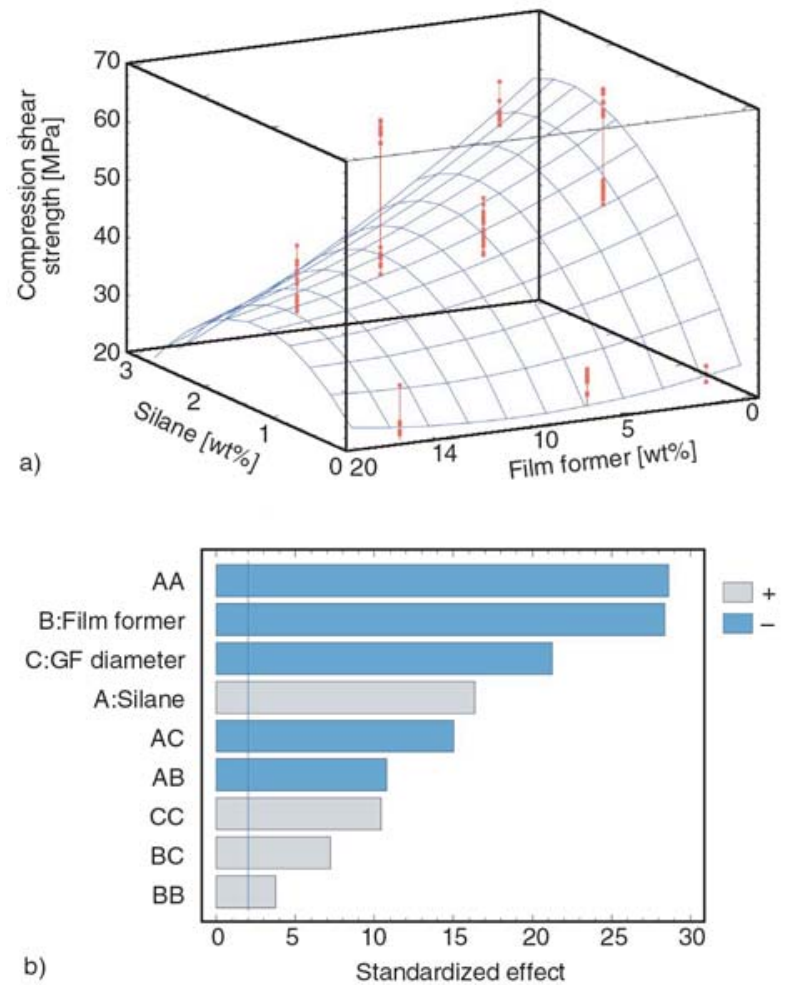

Figure 2. a) Estimated response surface for the compression shear strength of the GF/PP composites. The GF diameter was hold constant at $13 \mu \mathrm{m}$. The wt $\%$ of silane and film former refers to the solid content of the applied sizings. b) Pareto chart showing the statistically significant effects for the compression shear strength of the GF/PP composites. A, B, and $\mathrm{C}$ denote the main effects (silane and film former content of the sizing, and GF diameter). Statistically significant secondary effects, describing quadratic contributions of the main effects or interactions between different main effects, respectively, are denoted by a twoletter combination of the corresponding main effects.

pleteness the Pareto charts in Figure $1 b$ and $2 b$ show all statistically significant effects with P-values below 0.05. As can be seen in Figure 2b, for all three main effects a quadratic interaction can be found. However, in the case of the silane this is questionable since no experimental results are available for the high silane together with high film former contents in the sizing (cf. Table 1).

The regression equation for the best fit of the compression shear strength, $\sigma_{C S T}$, is described by Equation (2):

$$
\begin{aligned}
\sigma_{C S T}= & 173.9+46.04 \cdot A-2.02 \cdot B-20.86 \cdot C- \\
& 5.9 \cdot A^{2}-0.66 \cdot A \cdot B-1.32 \cdot A \cdot C+0.03 \cdot B^{2}+ \\
& 0.1 \cdot B \cdot C+0.73 \cdot C^{2}
\end{aligned}
$$


Table 1. Experimental matrix using a three level, three-factor factorial design, resulting in 15 experiments. '+', '0', and '-' indicate a high, intermediate and low level of the factor. For the amount of silane and film former the indications '-', ' 0 ', ' '+' refer to $0,1.5,3.0 \mathrm{wt} \%$ and $1.75,7.875,17.5 \mathrm{wt} \%$ solid content of the sizing, respectively. In the case of the GF diameter the indications '-', '0', and '+' are related to diameters of 11, 13 and $16.5 \mu \mathrm{m}$, respectively. The sizing of experiment 5 was not applicable for spinning of the GF, since a significant increase in viscosity upon mixing of silane and film former was observed.

\begin{tabular}{|c|c|c|c|}
\hline \multirow{2}{*}{ Experiment } & \multicolumn{2}{|c|}{ Factors } \\
\cline { 2 - 4 } & Amount of silane & Amount of film former & Glass fibre diameter \\
\hline 1 & 0 & 0 & 0 \\
\hline 2 & - & - & 0 \\
\hline 3 & + & - & + \\
\hline 4 & - & + & - \\
\hline 5 & + & 0 & - \\
\hline 6 & - & 0 & 0 \\
\hline 7 & + & 0 & + \\
\hline 8 & 0 & 0 & + \\
\hline 9 & - & 0 & - \\
\hline 10 & + & - & + \\
\hline 12 & 0 & + & + \\
\hline 13 & 0 & - & + \\
\hline 14 & 0 & + & + \\
\hline
\end{tabular}

For the fit of the CST by Equation (2) the coefficient of correlation is 0.98 .

\subsection{Effect of sizing formulation and glass fibre diameter on the composites interfacial strength}

The statistical analysis of the influence of the main effects highlighted their significance for transverse and compression shear strength of the composites. However, depending on the applied test method, the contribution of the main effects to the observed results is different. It should be noted that both test methods are primarily sensitive to the interphase region. As the fibre volume content and fibre orientation are comparable for all specimens tested, the results reflect the changes in the interphasial strength of the composites.

Not surprising, the absence of silane in the sizing results in composites with very poor mechanical performance. Without silane as adhesion promoter no covalent bonding between the fibre and matrix can be achieved. If silane is present, after hydrolysis of the alkoxy groups, covalent interactions with the inorganic surface of the GF are formed while its organofunctional groups can react with the matrix. The mechanical performance of the composites with an intermediate and high silane content in the sizing is similar, although the estimated response surfaces suggest a maximum at silane contents between 1.5 and $3 \mathrm{wt} \%$. It should be taken into account, that the intermediate concentration of $1.5 \mathrm{wt} \%$ silane was selected owing to the convention for response surface designs to choose the intermediate level as the arithmetic average between the lower and upper limit. However, in our earlier studies, lower silane concentrations around $1 \mathrm{wt} \%$ were found to yield similar mechanical performance for this system [31]. Therefore, the increased mechanical performance of the composites related to the silane content in the sizing could possibly be shifted towards lower silane contents. Moreover, for both regression equations the highest composite performance is predicted for the lower limits of the film former content and GF diameter in combination with silane contents between the intermediate and upper level. The physical significance of the proposed amount of silane is questionable, since this could be due to the parabolic nature of the model fit. However, it is known that excessive silane in sizings results in an increasing amount of physisorbed silane which can deteriorate the composite properties [10,35].

Figure 3 shows SEM micrographs of fractured surfaces of the composites with different sizing formulations after compression shear testing. In Figures $3 \mathrm{a}$ and $3 \mathrm{~b}$ the fractured surfaces of a composite with an intermediate silane and low film former 


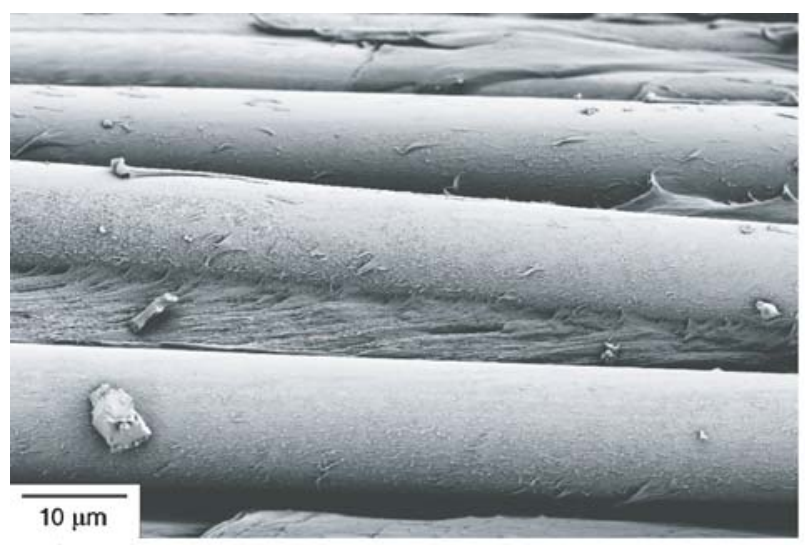

a)

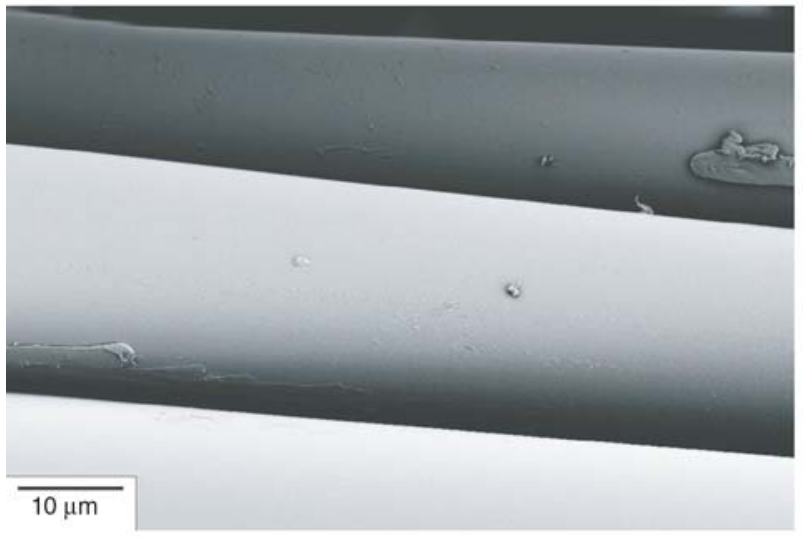

c)

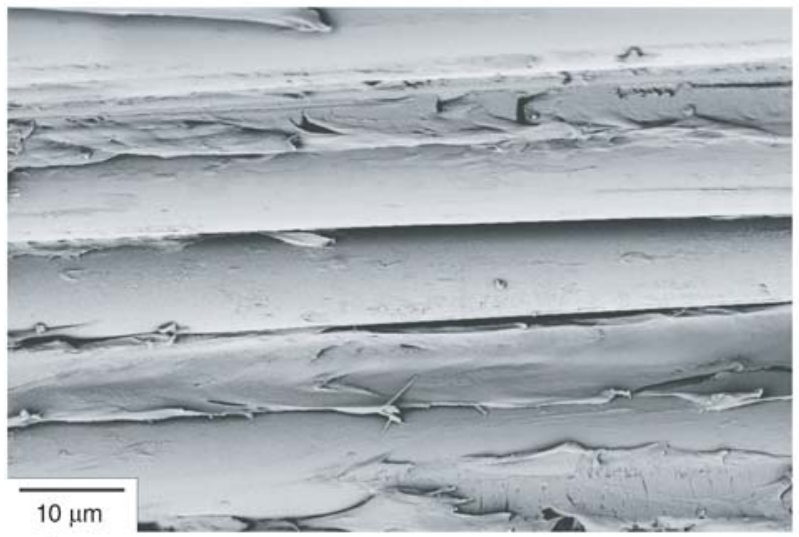

e)

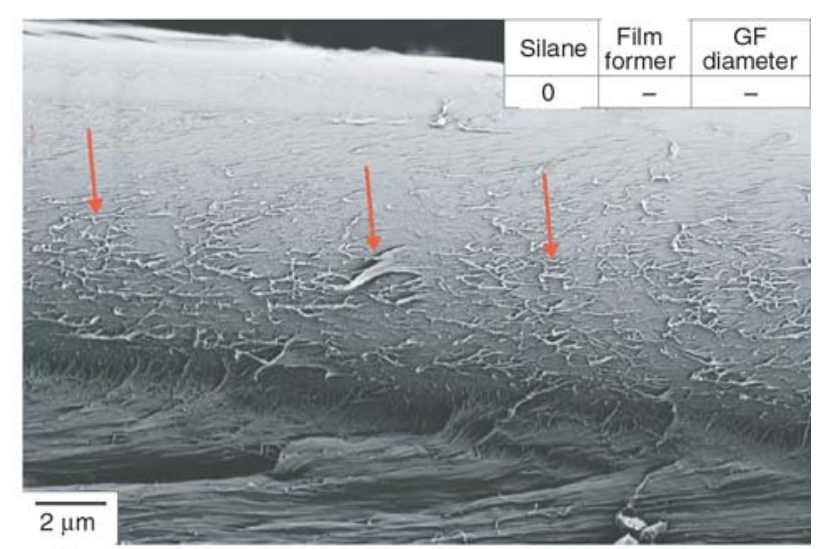

b)

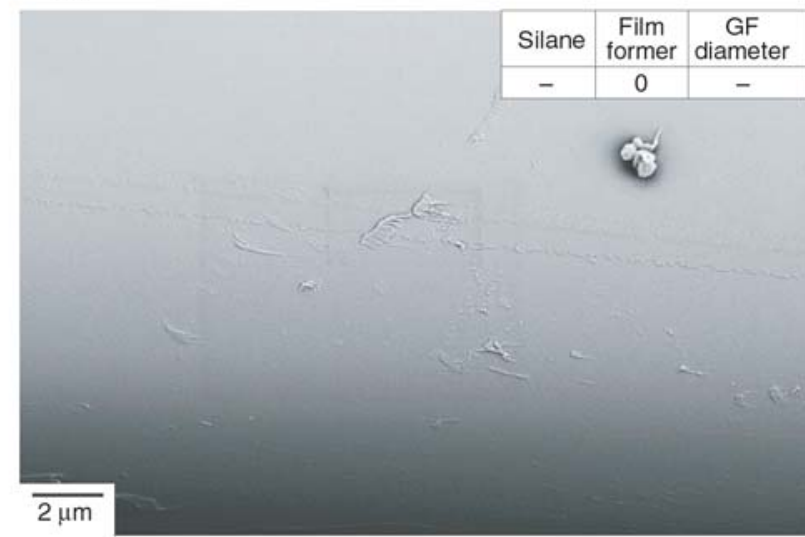

d)

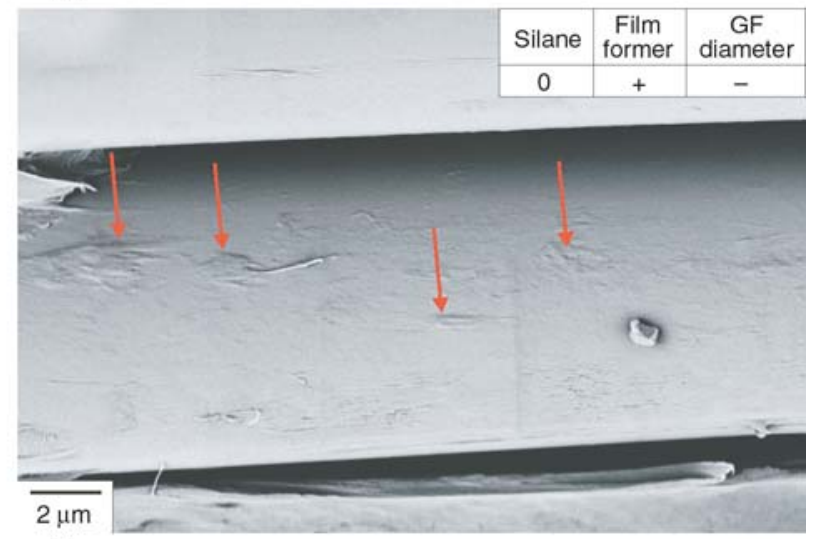

f)

Figure 3. SEM micrographs of fractured surfaces of unidirectional composites with different sizing formulations after compression shear testing. a), b): Experiment 11 - intermediate silane and low film former content. c), d): Experiment 6 - low silane and intermediate film former content. e), f): Experiment 12 - intermediate silane and high film former content.

content are shown. The characteristic feature of the fractured surfaces of this composite is an irregularly shaped GF surface with attached PP, clearly indicating the intense plastic deformation of the matrix PP next to the GF (marked with red arrows). The average CST of this composite was determined to be $63.7 \pm 1.7 \mathrm{MPa}$. For the sizing formulation without silane a drastic reduction in CST to $25.3 \pm 2.5 \mathrm{MPa}$ was determined. The associated fractured surfaces show a distinct picture with almost bare GF (cf. Figures 3c and 3d). This is indicative of an adhesive failure, related to the absence of the silane and the resulting poor GF/matrix adhesion. The micrographs of Figures $3 \mathrm{e}$ and $3 \mathrm{f}$ represent fractured surfaces of the composite with a CST of $42.1 \pm 1.8 \mathrm{MPa}$ owing to intermediate silane and high film former content in the sizing. Although SEM analysis of fractured surfaces is limited to qualitative conclusions, a distinct fracture mechanism compared to that of Figures $3 \mathrm{a}$ 
and $3 \mathrm{~b}$ predominates, resulting obviously in lower CST values. Compared to the fractured surface of the specimen with the low film former content in Figures $3 a$ and $b$, here, a different type of cohesive failure can be observed. Attached PP on the GF can be seen indicating a good bonding of the GF to its vicinity (marked with red arrows). However, the PP residues on the GF appear to be relatively homogeneous and show less plastic deformation than in Figures $3 \mathrm{a}$ and $3 \mathrm{~b}$. If a thicker film former layer on the GF is present, the GF/matrix interface is not necessarily the weakest region and failure can start within the film former layer due to insufficient shear strength of the film former PP or at the film former/matrix interface. It is known that upon consolidation of the composites the interdiffusion of the GF sizing and matrix polymer results in the formation of the interphase affecting the IFSS of composites [5]. For GF with a thicker film former layer the property gradient in the interphase is more pronounced since the range of interdiffusion is limited. As a consequence, in the vicinity of the fibre the interphasial properties are mainly determined by those of the film former, whereas with increasing distance to the GF interdiffusion with the matrix results in graded properties. This is similar to the results observed in [36], where for model composites made of GF/atactic PP (aPP) a cohesive failure was found indicating a strong fibre/matrix interface. However, the interfacial shear strength was limited by the insufficient matrix shear strength of the aPP resulting in poor overall values.

As can be inferred from the analysis of the main effects on the transverse tensile and compression shear strength, the latter one is much more sensitive to a variation in the film former content. The tensile load in transverse fibre direction results in a Mode I state of stress. This causes composites with strong interphases to fail at around $25 \mathrm{MPa}$, which is relatively close to the yield stress of neat PP of around $30 \mathrm{MPa}$. For the CST, values between 22 and $63 \mathrm{MPa}$ were observed and certain specimens showed some extent of plastic deformation in the load transmission region before they failed. Therefore, the state of stress is different from that of the transverse tensile stress and turns the film former related interphase thickness into the main factor for the load bearing capacity of the composites.

Besides the sizing formulation, the GF diameter, as the third factor, was also found to be of statistical significance for the mechanical properties of the composites. Both, transverse tensile and compression shear strength were found to increase with decreasing GF diameter. As both test methods are related to the interphasial properties, differences in GF strength associated with decreasing diameter of the GF can not account for the results. However, bearing in mind the constant GF weight fraction of $75 \%$, the interfibre distance decreases with decreasing GF diameter. Assuming inhomogeneities in the GF distribution, this results in matrix rich regions of larger dimensions for the specimens with the bigger GF diameters, compared to those with the smaller ones. A second issue related to a decreasing GF diameter is the specific surface. Decreasing the GF diameter from 16.5 to $11 \mu \mathrm{m}$ entails a gain in specific surface of $50 \%$. In this context, assuming a constant weight fraction of organic content of the fibre as well as a homogeneous coverage of the GF by the sizing, the thickness of the sizing layer on the GF increases for higher diameters. This effect is similar to an increased amount of film former in the sizing for constant GF diameter, which was shown previously to weaken the interphasial strength of the composites (cf. Figures 1 and 2).

The thickness of the sizing layer, $d_{s i z}$, can be estimated as a function of the GF diameter, $d_{G F}$, and the weight fraction of organic content on the fibre, $M_{s i z}$. The idealized cross sectional area of a sized GF, $A_{G F-s i z}$, is composed of the cross sectional area of the GF itself, $A_{G F}$, and the additional cross sectional area due to the sizing, $A_{\text {siz }}$. Replacing $A_{\text {siz }}$ by the density ratio between GF and sizing, $\rho_{G F} / \rho_{s i z}$, and multiplied by $M_{s i z}$ and $A_{G F}, A_{G F-s i z}$ can be written as Equation (3):

$$
A_{G F-s i z}=A_{G F}+\frac{\rho_{G F}}{\rho_{s i z}} \cdot M_{s i z} \cdot A_{G F}
$$

As $A_{G F-s i z}$ and $A_{G F}$ can be expressed by $\pi$ times the corresponding radius squared, the only unknown quantity in Equation (3) is the radius of the sized GF, $r_{G F-s i z}$. Rearranging the equation, $r_{G F-s i z}$ becomes Equation (4):

$r_{G F-s i z}=\sqrt{\frac{A_{G F}\left(\frac{\rho_{G F}}{\rho_{s i z}} \cdot M_{s i z}+1\right)}{\pi}}$

Now, the thickness of the sizing layer, assuming homogeneous coverage of the GF, can be calcu- 
lated by subtracting the radius of the GF, $r_{G F}$, from the radius of the sized GF, $r_{G F-s i z}$. For the density of the GF and the sizing, values of 2.56 and $0.95 \mathrm{~g} / \mathrm{cm}^{3}$, respectively, were used. Based on this estimation, Figure 4 shows the dependency of the sizing thickness on the GF diameter for different weight fractions of organic content on the fibre. From Figure 4 it can be seen that for constant organic contents on the GF the sizing thickness increases linearly for increasing GF diameters. For the composites prepared in this study, the variation of organic contents between 0.5 and about $2 \mathrm{wt} \%$, respectively, theoretically causes differences in the average sizing thickness in the range of $300 \%$. Moreover, the slope of the increase in thickness is steeper for higher weight fraction of organic content on the GF. As a maximum, considering $2 \mathrm{wt} \%$ weight fraction of sizing on the fibre and taking the experimentally varied diameters of 11 and $16.5 \mu \mathrm{m}$,

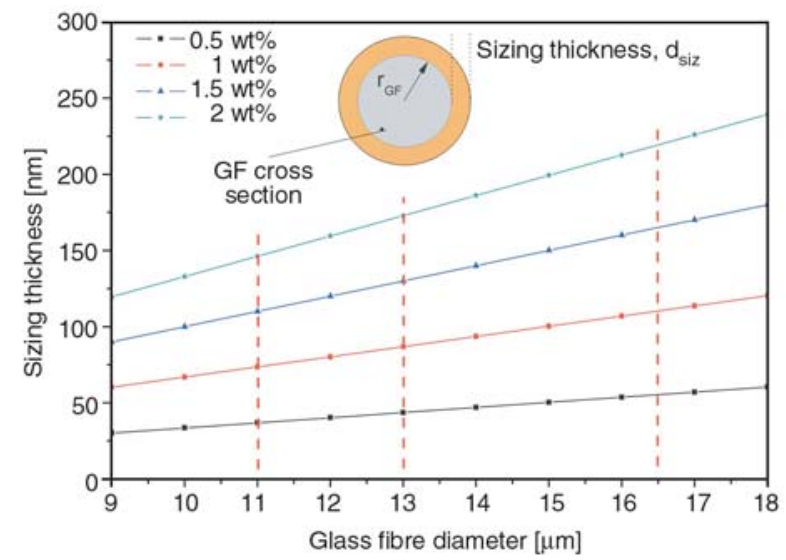

Figure 4. Calculated dependence of the sizing thickness on the GF diameter for different weight fractions of organic content on the GF assuming a homogeneously covered fibre. The vertical dotted lines represent the GF diameters, realized by stepwise variation of the haul-off speed during GF-spinning, i.e. lower, intermediate and high level of this factor. Similarly to this, 0.5 and $2 \mathrm{wt} \%$ organic content represent the upper and lower limits of the sizing content on the GF used for the manufacturing of the composites. respectively, the sizing thickness increases from 146 to $219 \mathrm{~nm}$, corresponding to an increase of $50 \%$. This explains why the GF diameter as one of the main effects in the factorial design can affect the composite strength similarly as the film former content in the sizing.

\subsection{Micro mechanical characterization of selected composites}

Besides the characterization of the composites in terms of transverse tensile and compression shear strength, micromechanical testing by means of SFPO tests was conducted in order to investigate the relationship between sizing formulation and adhesion strength for model composites. Four sets of differently sized GF were compared, only being different in terms of silane and film former content. During embedding, extreme care was taken to realize identical parameters, as it is known that a variation in temperature and atmosphere can affect the thermo-oxidative degradation of the small amount of matrix to a different extent. For the given matrix system this was evidenced by GPC measurements on SFPO samples embedded at different temperatures and atmospheres (results not discussed in detail here). Under Argon atmosphere, a change in embedding temperature from 255 to $230^{\circ} \mathrm{C}$ resulted in $M_{w}$ of 136300 and $156300 \mathrm{~g} / \mathrm{mol}$, respectively. Embedding at $255^{\circ} \mathrm{C}$ under ambient atmosphere without Argon results in a reduction of $M_{w}$ to $112200 \mathrm{~g} / \mathrm{mol}$. For the SFPO data presented in this study, all specimens were embedded under Argon atmosphere at $255^{\circ} \mathrm{C}$.

Table 2 shows the IFSS determined by SFPO measurements from the maximum force of the force-displacement curve divided by the perimeter of the embedded GF, as well as the corresponding data of the macro mechanical testing. From the SFPO data it can be inferred that changes in silane or film former content of the sizings are reflected in the IFSS

Table 2. Mechanical properties of selected composites based on micro and macro mechanical characterisation. For the amount of silane and film former the indications '-', '0', '+' refer to $0,1.5,3.0 \mathrm{wt} \%$ and $1.75,7.875,17.5 \mathrm{wt} \%$ solid content of the sizing, respectively.

\begin{tabular}{|c|c|c|c|c|c|}
\hline \multirow{2}{*}{ Experiment } & \multicolumn{2}{|c|}{ Sizing } & \multirow{2}{*}{$\begin{array}{c}\text { Interfacial shear } \\
\text { strength [MPa] }\end{array}$} & \multirow{2}{*}{$\begin{array}{c}\text { Transverse tensile } \\
\text { strength [MPa] }\end{array}$} & \multirow{2}{*}{$\begin{array}{c}\text { Compression shear } \\
\text { strength [MPa] }\end{array}$} \\
\hline & Silane & Film former & & & \\
\hline 6 & - & 0 & $3.2 \pm 1.3$ & $8.0 \pm 0.8$ & $25.3 \pm 2.5$ \\
\hline 7 & + & 0 & $8.4 \pm 2.3$ & $25.2 \pm 0.6$ & $53.2 \pm 1.4$ \\
\hline 11 & 0 & - & $7.2 \pm 1.3$ & $26.4 \pm 0.4$ & $63.4 \pm 1.7$ \\
\hline 12 & 0 & + & $5.2 \pm 1.4$ & $22.1 \pm 0.4$ & $42.1 \pm 1.8$ \\
\hline
\end{tabular}


of the samples showing a similar trend as for the macro mechanical testing data. The presented data agrees fairly well with results from literature [36] on the interfacial shear strength of GF/PP model composites. However, in contrast to the manuscript of Hoecker and Karger-Kocsis [36] the amount of film former was varied but not the processing conditions. Thus, the observed effect is mainly related to the thickness of the interphase, whereas the supramolecular structure of the PP is assumed to be similar for all cases. Moreover, for high film former contents the interphase is rather thick. Consequently, the 'bulk-properties' of the film former are more important due to the limited interdiffusion between matrix and sizing in the vicinity of the glass fibres, whereas for systems with low film former contents interdiffusion between matrix and sizing results in interphase with more graded properties.

Figure 5 relates the IFSS to the macro mechanical properties of the composites. For both test methods a correlation between the micro and macro mechanical properties can be seen. In the case of SFPO and transverse tensile strength the state of stress upon failure initiation is similar to Mode I [37]. Thus, a correlation between the two sets of data is not surprising. However, although the loading of the specimens for the CST testing is different from Mode I and plastic deformation before failure was found in the load transmission region, a similar trend as for the transverse tensile strength is observed.

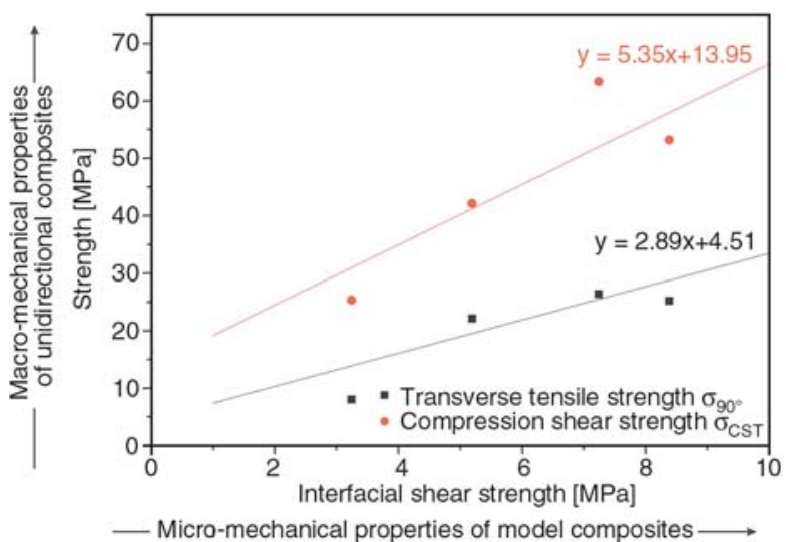

Figure 5. Correlation of the macro mechanical strength of the composites with the IFSS determined by SFPO tests on model composites

\subsection{Dynamic mechanical and thermal characterization of selected composites}

Besides the quasi-static characterization of composites, DMA was used to investigate the dynamical properties of the continuous fibre reinforced composites, influenced by different silane and film former contents. All samples were tested perpendicular to the fibre direction. Thus, the specimens can be regarded as a series connection of the elements GF-interphase-matrix-interphase. This allows to preferably detect interphase related differences, as not the GF stiffness is dominating the composites response like it is the case when testing in $0^{\circ}$ direction of the fibres. Figure 6 shows the storage modulus and $\tan \delta$ of selected composites with different silane and film former concentrations in the GF sizing. Taking a closer look at the storage modulus of the samples, it can be seen that one specimen strongly deviates in its behaviour from the others. Commonly, differences in storage modulus of fibre reinforced composites are related to issues like fibre weight fraction and fibre orientation, respectively, but here they do not account for the observed results as those factors are comparable for all composites tested. The main difference of this sample (experiment 6) compared to the others is that no silane was used in the sizing. As shown before for the quasi-static testing, sizings without silane result in very poor mechanical values (cf. Table 2). Here, at $-50^{\circ} \mathrm{C}$, the storage modulus is about $6 \mathrm{GPa}$, whereas the other specimens with an intermediate or high silane content show values in

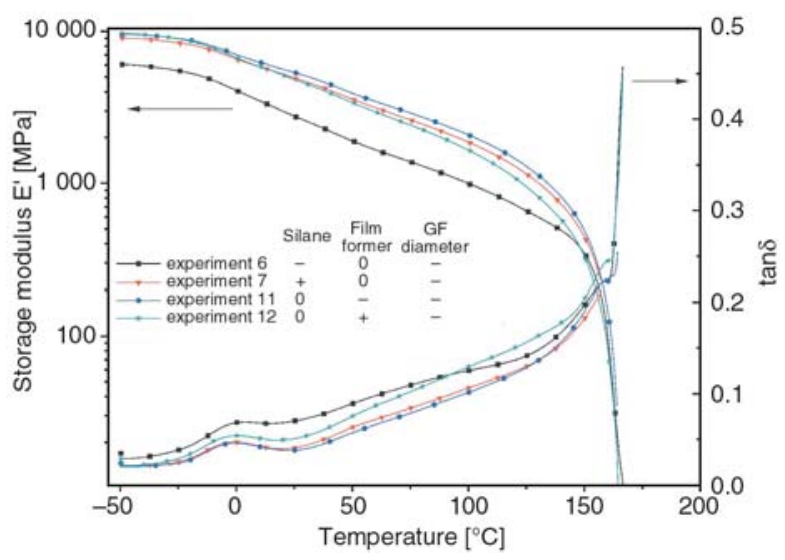

Figure 6. Storage modulus and $\tan \delta$ of unidirectional GF/PP composites with 75 wt $\%$ GF. Specimens were tested in $90^{\circ}$ direction. 
the range of $9 \mathrm{GPa}$. Obviously, the absence of silane affects the interphasial stiffness in a way that the storage modulus is shifted to lower values because no covalent bonding between GF and matrix takes place. At first glance, the other samples show comparable properties, however, above the glass transition temperature differences between the samples can be observed becoming more pronounced with increasing temperature. Although the absolute differences are relatively small they were confirmed by repeated measurements. Interestingly, the sample with the lowest film former content shows the highest storage modulus, followed by the ones with an intermediate and high level, respectively. This supports the findings of the quasi-static testing that a high film former content on the GF is not beneficial for the mechanical properties of a composite. GPC measurements revealed a lower molecular weight, $M_{w}$, of the film former compared to the matrix PP. $M_{w}$ was found to be 217600 and $147600 \mathrm{~g} / \mathrm{mol}$ for the PP matrix and the PP film former, respectively. Additionally, the melting behaviour of the film former and the matrix PP was characterized by DSC measurements and is shown in Figure 7. For the matrix PP the melting temperature was found to be $168.3^{\circ} \mathrm{C}$, whereas the melting temperature of the film former is approximately $8 \mathrm{~K}$ lower. Taking a melting enthalpy of $207 \mathrm{~J} / \mathrm{g}$ for a $100 \%$ crystalline PP [38], the crystallinity of the film former and the matrix PP calculate to 27 and $48 \%$, respectively. As the crystallinity of the film former is considerably lower, the presence of the film former in the interphase results in a higher content of amorphous PP, thus lowering the storage modulus of the composites. Therefore, thicker interphases due to a higher film

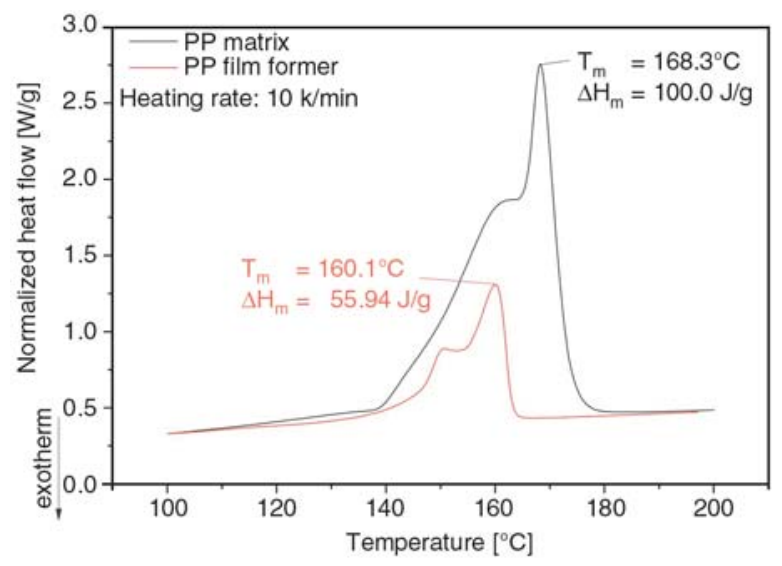

Figure 7. Thermal characterization of the melting behaviour of the PP film former and matrix PP former content on the GF affect the storage modulus.

\section{Conclusions}

According to a three level, three factor factorial design composites with different interphasial properties have been characterized by micro and macro mechanical test methods. The Pareto charts identify all three main effects as statistically important to the results of both transverse tensile and compression shear strength. Generally, sizings without silane coupling agents resulted in very poor mechanical performance, but no differences were found between the intermediate and high level of silane concentration in the sizing with regard to the mechanical properties. The film former concentration and GF diameter are negatively correlated with the interphasial strength of the composites, i.e. an increased film former concentration as well as an increased GF diameter were found to result in lower transverse tensile and compression shear strength, respectively. This is related to the fact that for constant sizing weight fractions on the fibres, a higher GF diameter is associated with a lower specific surface of the fibres, thus resulting in thicker average sizing layers on GF than compared to smaller diameters. As a consequence, the film former content and the GF diameter were found to affect the composite properties in the same way. Interphase sensitive SFPO tests and the thereby obtained interfacial shear strength values support the conclusions derived from the factorial design approach on the continuous fibre reinforced composites. Moreover, the characterization of the thermal properties of both, PP film former and matrix $\mathrm{PP}$, in combination with the determination of their molecular weight allows relating the properties of the film former to the interphasial behaviour, thus accounting for the different mechanical properties of the composites.

\section{Acknowledgements}

The authors are grateful for the support of this work by the Deutsche Forschungsgemeinschaft (DFG) within the framework of the collaborative research cluster SFB639 (subproject A1). Moreover, the authors are indebted to Dr. Häßler for performing the DMA and DSC measurements and helpful discussions. 


\section{References}

[1] Drzal L. T., Rich M. J., Lloyd P. F.: Adhesion of graphite fibers to epoxy matrices: I. The role of fiber surface treatment. The Journal of Adhesion, 16, 1-30 (1982).

DOI: $10.1080 / 00218468308074901$

[2] DiBenedetto A.: Tailoring of interfaces in glass fiber reinforced polymer composites: A review. Materials Science and Engineering A, 302, 74-82 (2001). DOI: $10.1016 /$ S0921-5093(00)01357-5

[3] Pukánszky B.: Interfaces and interphases in multicomponent materials: Past, present, future. European Polymer Journal, 41, 645-662 (2005).

DOI: $10.1016 /$ j.eurpolymj.2004.10.035

[4] Labronici M., Ishida H.: Toughening composites by fiber coating. A review. Composite Interfaces, 2, 199234 (1994).

[5] Gao S-L., Mäder E.: Characterisation of interphase nanoscale property variation in glass fibre reinforced polypropylene and epoxy resin composites. Composites Part A: Applied Science and Manufacturing, 33, 559-576 (2002).

DOI: $10.1016 / \mathrm{S} 1359-835 \mathrm{X}(01) 00134-8$

[6] Zhao F. M., Takeda N., Inagaki K., Ikuta N.: A study on interfacial shear strength of GF/epoxy composites by means of microbond tests. Advanced Composites Letters, 5, 113-116 (1996).

[7] Mäder E., Pisanova E.: Characterization and design of interphases in glass fiber reinforced polypropylene. Polymer Composites, 21, 361-368 (2000).

DOI: $10.1002 / p c .10194$

[8] Mäder E., Moos E., Karger-Kocsis J.: Role of film formers in glass fibre reinforced polypropylene - New insights and relation to mechanical properties. Composites Part A: Applied Science and Manufacturing, 32, 631-639 (2001).

DOI: $10.1016 / \mathrm{S} 1359-835 \mathrm{X}(00) 00156-1$

[9] Ishida H.: A review of recent progress in the studies of molecular and microstructure of coupling agents and their functions in composites, coatings and adhesive joints. Polymer Composites, 5, 101-123 (1984).

DOI: $10.1002 /$ pc. 750050202

[10] Zhuang R-C., Burghardt T., Mäder E.: Study on interfacial adhesion strength of single glass fibre/polypropylene model composites by altering the nature of the surface of sized glass fibres. Composites Science and Technology, 70, 1523-1529 (2010).

DOI: 10.1016/j.compscitech.2010.05.009

[11] Mäder E., Rausch J., Schmidt N.: Commingled yarns Processing aspects and tailored surfaces of polypropylene/glass composites. Composites Part A: Applied Science and Manufacturing, 39, 612-623 (2008). DOI: 10.1016/j.compositesa.2007.07.011

[12] Rausch J., Zhuang R. C., Mäder E.: Application of nanomaterials in sizings for glass fibre/polypropylene hybrid yarn spinning. Materials Technology: Advanced Performance Materials, 24, 29-35 (2009).

DOI: $10.1179 / 175355509 X 418016$
[13] Rausch J., Zhuang R-C., Mäder E.: Surfactant assisted dispersion of functionalized multi-walled carbon nanotubes in aqueous media. Composites Part A: Applied Science and Manufacturing, in press (2010). DOI: 10.1016/j.compositesa.2010.03.007

[14] Gao S., Mäder E., Plonka R.: Nanostructured coatings of glass fibers: Improvement of alkali resistance and mechanical properties. Acta Materialia, 55, 1043 1052 (2007). DOI: 10.1016/j.actamat.2006.09.020

[15] Sureeyatanapas P., Young R. J.: SWNT composite coatings as a strain sensor on glass fibres in model epoxy composites. Composites Science and Technology, 69, 1547-1552 (2009).

DOI: 10.1016/j.compscitech.2008.08.002

[16] Zhang J., Zhuang R. C., Liu J. W., Mäder E., Heinrich G., Gao S-L.: Functional interphases with multiwalled carbon nanotubes in glass fibre/epoxy composites. Carbon, 48, 2273-2281 (2010). DOI: 10.1016/j.carbon.2010.03.001

[17] Gao S-L., Zhuang R-C., Zhang J-W., Liu J., Mäder E.: Glass fibers with carbon nanotube networks as multifunctional sensors. Advanced Functional Materials, 20, 1885-1893 (2010).

DOI: 10.1002/adfm.201000283

[18] Rausch J., Mäder E.: Health monitoring in continuous glass fibre reinforced thermoplastics: Manufacturing and application of interphase sensors based on carbon nanotubes. Composites Science and Technology, in press (2010).

DOI: 10.1016/j.compscitech.2010.05.018

[19] Boudewijn J. R., Scholtens B. J. R., Brackman J.: Influence of the film former on fibre-matrix adhesion and mechanical properties of glass-fibre reinforced thermoplastics. The Journal of Adhesion, 52, 115-129 (1995). DOI: $10.1080 / 00218469508015189$

[20] Kim J-K., Sham M-L., Wu J.: Nanoscale characterisation of interphase in silane treated glass fibre composites. Composites Part A: Applied Science and Manufacturing, 32, 607-618 (2001). DOI: $\underline{10.1016 / \mathrm{S} 1359-835 \mathrm{X}(00) 00163-9}$

[21] Hodzic A., Kim J. K., Lowe A. E., Stachurski Z. H.: The effects of water aging on the interphase region and interlaminar fracture toughness in polymer-glass composites. Composites Science and Technology, 64, 2185-2195 (2004).

DOI: 10.1016/j.compscitech.2004.03.011

[22] Häßler R., Mühlen E.: An introduction to $\mu \mathrm{TA}{ }^{\mathrm{TM}}$ and its application to the study of interfaces. Thermochimica Acta, 361, 113-120 (2000).

DOI: $\underline{10.1016 / \mathrm{S} 0040-6031(00) 00552-9}$

[23] Mallarino S., Chailan J. F., Vernet J. L.: Interphase investigation in glass fibre composites by micro-thermal analysis. Composites Part A: Applied Science and Manufacturing, 36, 1300-1306 (2005). DOI: 10.1016/j.compositesa.2005.01.017 
[24] Mäder E., Grundke K., Jacobasch H., Wachinger G.: Surface, interphase and composite property relations in fibre-reinforced polymers. Composites, 25, 739744 (1994) DOI: $10.1016 / 0010-4361(94) 90209-7$

[25] Mäder E., Jacobasch H., Grundke K., Gietzelt T.: Influence of an optimized interphase on the properties of polypropylene/glass fibre composites. Composites Part A: Applied Science and Manufacturing, 27, 907912 (1996). DOI: $10.1016 / 1359-835 X(96) 00044-9$

[26] Wu H. F., Dwight D. W., Huff N. T.: Effects of silane coupling agents on the interphase and performance of glass-fiber-reinforced polymer composites. Composites Science and Technology, 57, 975-983 (1997). DOI: $10.1016 / \mathrm{S} 0266-3538(97) 00033-\mathrm{X}$

[27] Thomason J. L.: The interface region in glass fibrereinforced epoxy resin composites: 3 . Characterization of fibre surface coatings and the interphase. Composites, 26, 487-498 (1995). DOI: $10.1016 / 0010-4361(95) 96806-\mathrm{H}$

[28] Jones F. R.: Interphase formation and control in fibre composite materials. Key Engineering Materials, 116117, 41-60 (1996).

DOI: 10.4028/www.scientific.net/KEM.116-117.41

[29] Thomason J. L., Adzima L. J.: Sizing up the interphase: An insider's guide to the science of sizing. Composites Part A: Applied Science and Manufacturing, 32, 313-321 (2001). DOI: $10.1016 / \mathrm{S} 1359-835 \mathrm{X}(00) 00124-\mathrm{X}$

[30] Shokoohi S., Arefazar A., Khosrokhavar R.: Silane coupling agents in polymer-based reinforced composites: A review. Journal of Reinforced Plastics and Composites, 27, 473-485 (2008). DOI: $\underline{10.1177 / 0731684407081391}$
[31] Mäder E., Rothe C., Brünig H., Leopold T.: Online spinning of commingled yarns- Equipment and yarn modification by tailored fibre surfaces. Key Engineering Materials, 334-335, 229-232 (2007).

DOI: 10.4028/www.scientific.net/KEM.334-335.229

[32] Schneider K., Lauke B., Beckert W.: Compression shear test (CST) - A convenient apparatus for the estimation of apparent shear strength of composite materials. Applied Composite Materials, 8, 43-62 (2001).

[33] Mäder E., Gao S-L., Plonka R., Wang J.: Investigation on adhesion, interphases, and failure behaviour of cyclic butylene terephthalate $\left(\mathrm{CBT}^{\circledR}\right) /$ glass fiber composites. Composites Science and Technology, 67, 3140-3150 (2006).

DOI: 10.1016/j.compscitech.2007.04.014

[34] Wilkinson L:. Revising the Pareto chart. The American Statistician, 60, 332-334 (2006). DOI: $\underline{10.1198 / 000313006 X 152243}$

[35] Wu S.: Polymer interface and adhesion. Marcel Decker, New York (1982).

[36] Hoecker F., Karger-Kocsis J.: On the effects of processing conditions and interphase of modification on the fiber/matrix load transfer in single fiber polypropylene composites. The Journal of Adhesion, 52, 81-100 (1995) DOI: $\underline{10.1080 / 00218469508015187}$

[37] Zhandarov S., Mäder E.: Characterization of fiber/ matrix interface strength: Applicability of different tests, approaches and parameters. Composites Science and Technology, 65, 149-160 (2005). DOI: 10.1016/j.compscitech.2004.07.003

[38] Ehrenstein G. W., Riedel G., Trawiel P.: Praxis der thermischen Analyse von Kunststoffen. Hanser, München (2003). 